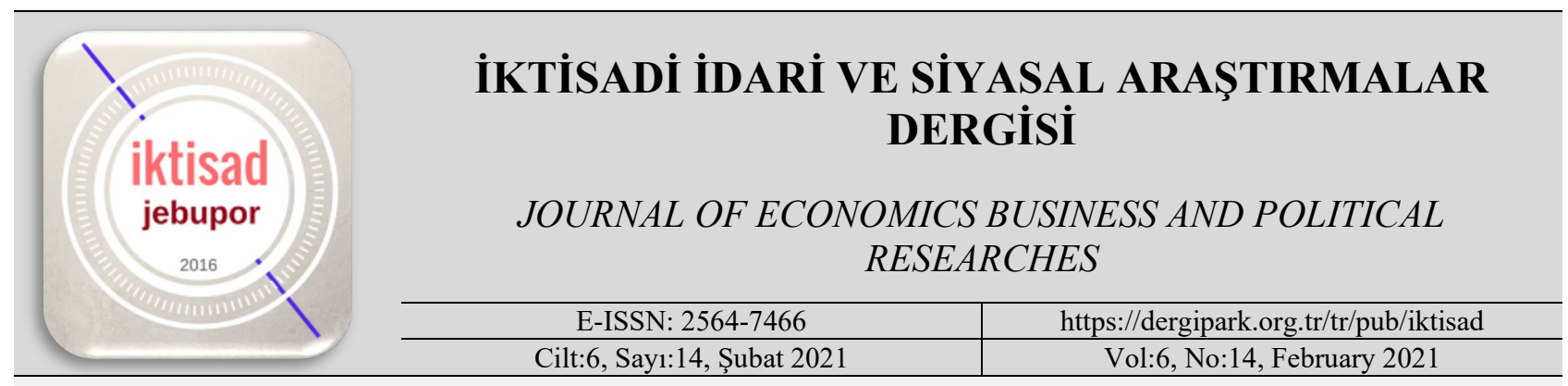

\title{
Muhasebe Bilgi Kalitesinin Maliyet Analizi Süreçlerine Etkisi: Muhasebe Meslek Mensupları Üzerine Bir Araştırma
}

The Effect of Accounting Information Quality on Cost Analysis Processes: A Research on Accounting Professionals

$\ddot{\mathbf{O}} \mathbf{z}$

Makale Bilgileri

Makale Türü: Araştırma Makalesi

Geliş Tarihi: 06.01.2021

Kabul Tarihi: 22.02.2021

(C) 2021 IKKTISAD Tüm hakları saklıdir. \section{(i) (5)}

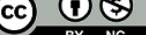

Paper Type:

Research Paper

Received:

06.01.2021

Accepted:

22.02.2021

(C) 2021 JEBUPOR All rights reserved.

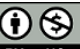

Bu çalışmada muhasebe bilgilerinin kalitesinin işletmenin önemli süreçlerinden biri olan maliyet analizi süreçlerine etkisi üzerine literatür taraması yapılmıştır. Gaziantep Bölgesinde bulunan muhasebe meslek mensuplarının, muhasebe bilgilerinin kalitesinin maliyet analizi süreçlerine etkisine ilişkin görüşlerinin belirlenmesi amaçlanmıştır. Ilgili araştırmada anket yöntemi benimsenmiştir. Anket sonucunda ulaşılan veriler SPSS 24.0 paket programı ile analiz edilmiştir. Çalışmanın sonucunda maliyet kontrolü, faaliyet planlaması, mamul maliyetinin hesaplanması, rekabet gücü ve iş süreçlerinin kolaylaştırılması konularında sunulan muhasebe bilgilerinin kalitesinin, muhasebe meslek mensuplarının eğitim durumlarına göre anlamlı bir farklılı gösterdiği sonucuna ulaşılmıştır. Kaliteli muhasebe bilgilerinin, maliyet analizinin temelini oluşturan doğru fiyatlandırma, maliyetlerin azaltması ve maliyetlerin kontrolü noktasında pozitif etkiler bıraktı̆̆ kanısı oluşmuştur. İsletmelerin sürdürebilirliğinin, etkin maliyet analizi ile mümkün olacă̆ı açıktır. Mali faaliyetlerin planlanması, mamul maliyetlerinin hesaplanması, genel üretim giderlerinin dağıtımı ve bütçeleme sistemi muhasebe bilgisinin kaliteli olması ile daha isabetli kararların alınabileceğini göstermektedir.

Anahtar Kelimeler: Muhasebe Bilgi Sistemi, Muhasebe Bilgi Kalitesi, Maliyet Analizi.

\begin{abstract}
In this study, a literature review has been made on the effect of the quality of accounting information on cost analysis processes, one of the important processes of the business. It is aimed to determine the opinions of the professional accountants in the Gaziantep Region on the effect of the quality of accounting information on cost analysis processes. The survey method has been adopted in the related research. The data obtained as a result of the survey were analyzed with the SPSS 24.0 package program. As a result of the study, it is concluded that the quality of the accounting information provided in the subjects of cost control, activity planning, calculation of product cost, competitiveness and facilitation of business processes differs significantly according to the education levels of accounting professionals. It has been concluded that good quality accounting information has positive effects on correct pricing, cost reduction and cost control, which are the basis of cost analysis. It is clear that the sustainability of businesses will be possible with effective cost analysis. Planning of financial activities, calculation of product costs, distribution of general production expenses and budgeting system show that more accurate decisions can be made with the quality of accounting information.
\end{abstract}

Keywords: Accounting Information, System, Accounting Information Quality, Cost Analysis.

Atıf/ to Cite (APA): Karahan, M. \& Kestane, A. (2021). Muhasebe Bilgi Kalitesinin Maliyet Analizi Süreçlerine Etkisi: Muhasebe Meslek Mensupları Üzerine Bir Araştırma. Íktisadi İdari ve Siyasal Araștırmalar Dergisi, 6(14), 117-129 


\section{Extended Abstract}

\section{Research Purpose:}

In this study, it is aimed to determine the opinions of the Accounting Professionals operating in Gaziantep on the effect of accounting information quality on cost processes.

\section{Method:}

The data for the research was applied face-to-face to independent accountant financial advisors in 2020 using the survey technique. A previously proven study (Cohen, Manion, \& Marrison, 2007) is used to create the content of the questionnaires. In addition, while preparing the survey questions, the opinions of the Accounting Professionals Chamber managers and especially the studies of Aktaş and Turan (2019) are used. The created questionnaire form consisted of 22 questions and 2 groups. Each statement is coded from 1 to 5, and their degree of agreement is "Strongly Disagree", "Disagree", "Neither Agree Nor Disagree", "Agree" and "Strongly Agree". In the first group; to determine the demographic and descriptive characteristics of the participants; There are statements regarding the position, age, gender and educational status of the respondent. In the second group of questions, there are 17 statements about the effect of accounting information quality on cost analysis processes. The data obtained from the questionnaires were collected, organized and reviewed and coded in accordance with the purpose and nature of the research. In terms of the implementation, 250 questionnaires were distributed and 152 of the 160 questionnaires obtained were deemed appropriate for evaluation. The obtained data were encoded in the "Microsoft Excel 2016" program and transferred to the "SPSS (Statistical Package for the Social Sciences) 24.0" program, and appropriate analyzes were made in this program (reliability analysis, descriptive statistics, frequency distribution, non-parametric variance analysis; Kruskal Wallis $\mathrm{H}$ test and Mann-Whitney $\mathrm{U}$ test) and the results were arranged and evaluated.

\section{Findings:}

It is concluded that the quality of the accounting information presented in the subjects of cost control, activity planning, calculation of product cost, competitiveness and facilitation of business processes differs significantly according to the education status of Accounting Professionals.

\section{Conclusion:}

It is aimed to determine the interaction between the accounting information quality and cost analysis processes by the Accounting Professionals in the Gaziantep Region. It has been observed that the high quality of accounting information increases the job satisfaction of accounting professionals and benefits the interaction between their units within the company. In addition, it has been concluded that quality accounting information has positive effects on correct pricing, cost reduction and cost control, which are the basis of cost analysis. 


\section{Gíriș}

Bilginin saf hali olarak karşılanan veri kavramı, işleme süzgecinden geçirilmemiş bir bilgi olarak ifade edilebilmektedir. Verinin tanımına bakıldığında gerçeklerden, fikirlerden ve komutlardan gelen donelerin makineler veya insanlar tarafindan yorumlaması ya da işlemesine uygun olacak şekilde soyutlanması olarak görülmektedir (Elitaş, 2013: 44). Verinin bilgiye dönüşmesi; verinin toplanmas1, sinıflandırılması, düzenlenmesi, özetlendirilmesi, iletilmesi, yeniden elde edilmesi ve saklanması süreçlerinden geçerek oluşmaktadır. Veri öncelikle, belgelerden, anketlerden ve farklı araçlardan bir araya getirilmektedir. Toplanan veriler sınıflandırılıp düzenlenerek anlamlı bir hale getirilir. İşlem görmüş veri bilgi haline geldiğinde, anlaşılabilmesi için özetlenir. Ortaya çıkan anlaşılır bilgi daha sonra kullanılmak üzere doğru bir şekilde saklanır. Bu çerçevede bilginin alıcıya fayda sağlayabilmesi için zamanı, yeri, biçimi, doğru olmalı ve doğru kişiye ulaştırılması gerekmektedir (Keleş, 2018: 3). Perakende, üretim ve hizmet sektörlerine yer alan işletmeler risklerini, avantaj ve zayıf yönleri, verimliliklerini belirleyerek arttırmak için geniş çaplı analiz ve verileri kullanarak bunlardan faydalanmayı istemektedirler (Yılmaz, Bülbül, \& Atik, 2017: 81).

Bilgi, verilerin belirlenmiş amacına ulaşma doğrultusunda kullanılabilir hale dönüştürülmüş olarak tanımlanabilir. Günümüzde işletmelerde bilgiler işletme içerisinde geçen aşamalar ciddi bazı sorumluluklar almaktadır. Otomasyon ve bilgisayar teknolojilerinde 1990'lı yıllarda kullanılmasının artmasıyla bu bilgilerin yönetimi analog sistemden dijital sisteme geçişi olmuştur. Bu nedenle, işletmelerde önem kazanan veri tabanı kullanımının sonucunda ham veri olarak bilgiler dijital ortamda bilgisayarlarda depolanmaya başlanmıştır (Ala vd., 2016: 140). Bilgi, karar alma süreçlerinde günümüzdeki işletmelerde rolü önemlidir. İşletmelerin başarısında bilgi kalitesi önemi kritiktir. Bilgiyi üretmede işletmelerin muhasebe bilgi sistemi, işletmeler aracılığıyla planlama, iş süreçlerini ve değerlendirme, finansal seviyelerini tanımlamada kullanılan kaliteli bilgiyi ortaya çıkarmaktadır (Demir, 2010: 142). Değişen sistemle beraber rekabet şartları ve yaşamdaki teknolojik gelişmeler işletmelerin geleceklerini ve varoluşlarını derinden etkileyerek bu süreçte ortaya çıkartılan kaliteli işleyişlerin verimliliği ve etkin olması bakımından muhasebe bilgileri işletmelerin vazgeçemediği parçalarından biri olmuştur. Kaliteli muhasebe bilgisi kullanıcıların isabetli ve doğru karar alabilmelerinde önemli rol üstlenerek işletmenin varlığ üzerinde önem taşıması hayati olup bu bakımdan işletmelerin denetim içi faaliyetlerinin verimli ve etkin bir biçimde sürdürülmesi sonucunda kaliteli muhasebe bilgisinin arttırılması sağlanmaktadır. Söz konusu kaliteli muhasebe bilgilerinin ayrıca; bu bilgilerin kalitesi üzerinde, bilgilerin; gerçekliği, gerçeğe ve ihtiyaca uygunluğu, güvenilir olması gibi birçok önemli unsurlar etki etmektelerdir. Bu bilgililer işletme dışında ve işletme içinde karar almada kullanıcıları etkileyebilmektedir (Kurnaz vd., 2018: 150). Finansal tabloları oluşturan işletmeler bir dönem sonucunda muhasebe süreçleri farklı bilgi kullanıcılar ve karar alıcılara sunarlar. Karar vericiler ve bilgiyi kullananlar bu finansal tabloları yararlı hale dönüştürmek amacıyla hedeflerine uygun kullanmaya çalışırlar. Bu değerlendirmeler sonucunda ortaya çıkan çıkarımları ve sonuçlara göre hedef belirledikleri amaçlara yönelik adım atarlar. Örneğin işletmenin bir iş üzerinde yatırım yapıp yapmayacağına bu kaliteli bilgiler ile karar verilir (Elitaş, 2013: 42). İşletmelerin rekabet üstünlüklerini sağlamada değişen ortamda günümüzde işletme faaliyetlerini etkili bir biçimde sürdürebilmeleri için; günümüzün önemli bir etkeni olan bilgiye, yani önemli olarak kaliteli bilgiye ulaşmalarına dayanmaktadır. Bu da günümüzde rekabet ortamının değişmesi işletmelerin başarı elde etmelerinde kaliteli bilginin önemini, işletmelerin performanslarında etkili olması, işletmenin rekabet ortamında avantajı ortaya çıkarabilmesi ve geleceğe yönelik işletmenin üst yönetimi tarafından alınan kararlar aşamasında bu kaliteli bilgiler kilit rol üstlenmektedir (Kurnaz vd., 2018: 151).

Yukarıda yapılan açıklamalardan hareketle bu çalışmada Gaziantep ilinde faaliyet gösteren muhasebe meslek mensuplarının muhasebe bilgi kalitesinin maliyet süreçleri üzerindeki etkisine yönelik görüşlerinin belirlenmesi amaçlanmıştır. İlgili konulara yönelik olarak literatürde farklı alanlarda çeşitli çalışmaların yapıldığı görülmektedir. Dolayısıyla çalışmanın teması kapsamında önemli kabul edilen çalışmalar aşağıda açıklanmaktadır. 
Kurnaz vd. (2018) iç denetim ve bilgi ifşası ilişkisini muhasebe bilgi kalitesi çerçevesinde değerlendirmiş; Zhai ve Wang (2016) muhasebe bilgi kalitesi ve sermaye yatırımı seçimi arasındaki ilişkiyi değerlendirmeye yönelik; Ren (2016), yatırım etkinliğinin belirlenmesinde muhasebe bilgi kalitesinin etkisini yönelik; Susanto (2015), üniversitelerde muhasebe bilgi kalitesini etkileyen faktörlere yönelik; Fardinal (2013), kamu kurumlarında, muhasebe bilgi sistemleri kalitesi ve muhasebe bilgi kalitesi üzerinde iç kontrol sisteminin etkisine yönelik; Demir (2010), muhasebe bilgi sistemlerinde üretilen bilgilerin kalitesinin belirlenmesine yönelik; Chan vd. (2006), muhasebe bilgi kalitesinin, tahakkukların yanlış fiyatlandırılması üzerindeki etkisine yönelik çalışmalar yapmışlardır. Handy ve Mook (2011) gönüllü hizmet eden kuruluşlarda fayda-maliyet analizine yönelik; Basu ve Manning (2009) yeni nesil sağlık hizmetlerinde maliyet analizine yönelik; Kudra ve Ratti (2006) enerji alanında maliyet analizine yönelik; Karasioğlu ve Çam (2008) sağlık işletmelerinde maliyet analizine yönelik çalışmalar yapmışlardır. Literatürde yapılan çalışmalar incelendiğinde, muhasebe bilgi kalitesi ve maliyet analizi konusunu bütünleşik olarak ele alan bu çalışmanın, ayrı bir önem taşıdığını belirtmekte yarar görülmektedir. Bu çalışma iki ana bölümden oluşturulmuştur. Birinci bölümde muhasebe bilgi sistemi, muhasebe bilgi kalitesi ve maliyet analizine yönelik kavramsal bir çerçeve oluşturulmuştur. İkinci bölümde ise çalışmada gerçekleştirilen uygulamaya yer verilmiştir.

\section{MUHASEBE BILLGISİ VE MUHASEBE BILLGI SISTEMI}

Muhasebe, örgüt içerisinde örgüt için gereken kaynakların oluşumu, oluşan kaynakların kullanım biçimlerini, bu kaynaklarda işlemler sonucunda ortaya çıkan azalış veya artışları ve finansal açıdan örgütün performansını ortaya çıkaran bilgileri sunan ve bu bilgileri ilgili kuruluş ve kişilere ulaştıran bir "bilgi sistemi"dir (Sevilengül, 2020: 3). Muhasebe, işletmenin kaynak ve sahip olduğu varlıkların hareketlerini inceleyerek kayıt altına alma, özetleme ve rapor etme gibi farklı fonksiyonlarda inceleyerek takip eden sistemdir (Dinç \& Abdioğlu, 2009: 158).

Muhasebe tanımlarına bakıldığında dikkat çeken en belirgin konu bilgidir. Bilgi, "araştırma, öğrenme veya gözleme dayalı yollarlar elde edilen gerçek" veya "insanların zihinsel çalışması sonucunda ortaya çıkan düşünce biçimi, ürün, malumat" olarak tanımlanmıştır (Türk Dil Kurumu, 2020). Muhasebe bilgisi, işletme içerisinde ilgili bilgilerin ekonomik faaliyetleri açısından değerlendirilerek, bu değerlendirilen bilgileri rapor haline getirerek işletme dışı ve içi ilgili kullanıcılara sunum amacı ile kullanılmaktadır (Dinç ve Abdioğlu, 2009: 162). Bu bağlamda Üretilen bilgilerin muhasebe bilgi sistemlerinde, etkin şekilde işletme faaliyetlerinin yürütülmesinde ve işletmede alınan kararların doğru alınmasında büyük rolü vardır (Demir, 2010: 142). Muhasebe bilgisinde temel amaç, işletme içerisinde yöneticilerin işletmenin kararlarını alma süreçlerinde ve işletmenin geleceğinde neler yapacağına dair tahminlerde kullanılmak üzere bilgileri sunar. $\mathrm{Bu}$ sebepten dolayı muhasebenin işletme için etken ve önemli rolde konum almaktadır. İşletmenin muhasebe bilgilerinde finansal çerçevesinin tüm kademelerinde zorunlu bir sistemdir (Dinç ve Abdioğlu, 2009: 167). Muhasebe bilgisi, işletmede bilgiyi kullananlara finansal olarak tablolar vasıtası ile iletilmektedir. $\mathrm{Bu}$ muhasebe bilgilerinin güvenilirliği ve doğruluğu; diğer bilgi kullanıcılarının, borç verenler ve yatırımcılarının tutarlı ve doğru kararlar vermesinde yardımcı olunmaktadır. Muhasebe sistemindeki bilgilerin kalitesi, doğruluğu ile ilgili genel olarak kabul görmüş muhasebe bilgilerinin ışığında, doğru, gerçek ve bilgi kullanıcılarına ihtiyaçlarını karşılamak amacıyla uygun bir halde olması gerektiği söylenebilir (Arıcı ve Karğın, 2017: 229).

Muhasebe bilgi sistemleri işletme bilgi sistemleri içerisinde en geniş ve eski kapsamlı olanıdır. Muhasebe bilgi sistemlerinde var olan bilgiler işletme içinde ve dişında farklı kullanıcılar taraflarından kullanılabilmektedir. Muhasebe bilgi sistemlerinde üretilen kalite kriterleri bilgiyi kullananların kararlarını almalarında doğrudan doğruya etki etmektedir. Muhasebe bilgilerinin çeşitli gruplar veya bireylere iletilmesi durumlarında, muhasebe bilgilerinin çok olmasından ziyade kaliteli olması temeli alınması ve bu iletilen muhasebe bilgilerinin nitelikli olup ihtiyaçları tam olarak karşılaması gerekmektedir. Dolayısıyla bu kaliteli bilgilerin kullanıcıların kararlarını almalarında 
isabetli olabilmesi için muhasebe bilgilerinin kaliteli olmalarının önemi gerekmektedir (Acar \& Özçelik, 2011: 10).

Kullanıcılar tarafından gereksinim görülen bilgileri üretmek için muhasebe bilgi sistemleri, nitelik olarak finansal faaliyetler ile alakalı verileri; gerek görüldüğünde kullanılmak amacı ile toplayan, işlem sonucunda raporlara ve bilgiye dönüştüren, kaliteli, güvenilir ve doğru bilgilerin çıtı edilmesini amaçlayan bu süreçleri takip ederek kontrol altında tutan bilgi sistemidir (Demir, 2010: 143). Bilgi teknolojileri yoğun bir şekilde muhasebe bilgi sistemlerinde kullanılmaktadır. Bu sebepten dolayıdır ki muhasebe bilgi sistemlerinde kullanılan sitem ve paketler uygun özelliklere sahip olmaları gerekmektedir. Yararlanıcılar ve kullanıcılar açısından muhasebe bilgi sistemleri; muhasebe bilgi sistemlerinde muhasebe personeli, iç denetleyiciler, diş denetleyiciler, bilgi işlem bölümündeki personeller, paydaşlar, veri yöneticileri ve bilgi kullanıcılarıdır. Bu kaliteli muhasebe bilgi sistemlerinin amacı, potansiyel olan yatırımcılar, mevcut durumdaki paydaşlar, kredi ve borç verenler, diğer taraftan işletmeye destek kaynak sağlamak amacı ile kararlar verilirken ve işletme yönetimlerine yatırım kararlarında faydalı olacak finansal açıdan kaliteli bilgiyi sağlamaktadır (Ala, Kahraman, \& Sümer, 2016: 145).

\section{MUHASEBE BİLGí KALİTESİ}

Muhasebe bilgilerinin kalitesi, karşılaştırılabilir, güvenilir, doğru, finansal tabloların anlaşılabilir ve uygunluk şeklindeki özellikleri bir arada bulundurabilme düzeyi ile ifade edilmesiyle çok boyutlu bir kavram olmaktadır (Kaya, 2019: 157). Kullanıcılara faydalı olabilmeleri için muhasebe bilgilerinin sahip olunması gerekli özellikleri ve nitelikleri, kavramsal çerçevede ve destekleyici ve temel niteliksel olarak özellikleri ikiye ayrılmıştır. Niteliksel temel özellikler, "gerçeğe uygun sunum" ve "ihtiyaca uygunluk (ilgililik)" olarak belirtilmiştir. Bu çerçevede finansal tablolar kullanılarak elde edilen bilgilerin kullanıcılar üzerinde karar alma aşamasında rol oynaması ve kullanım şekline uygunluğunu ifade etmektedir. (Karğın \& Arıc1, 2015: 3). Kalitesi yüksek muhasebe bilgilerinin olduğu işletmelerde, işletmenin sermaye maliyetinde düşüş olduğu görülür. Bu durum muhasebe bilgi kalitesinin önemini ifade etmektedir. Sermaye yatırımlarında tasarrufların yatırıma dönüşmesi, iyi değerlendirilen finansal görünümün, sağlıklı işlenen finansal piyasaların ilerlemelerinde, doğru orantılı olan muhasebe bilgi kalitesi önemli ve değerlidir (Gençoğlu \& Ertan, 2012: 3). Muhasebe bilgi kalitesi alanında ulusal ve uluslararası gelişmelerin yaşanmasıyla birlikte bu gelişmeler farklılıklar göstermektedir. Her ne kadar yaşanan gelişmeler farklılık gösterse de muhasebe bilgi kalitesinin amacı, muhasebe bilgilerini kullananlar için firma durumunun gerçeği yansıtan, şeffaf, ekonomik gerçeklerin doğru olarak sunulmasını sağlamasıdır (Dalkılıç, 2019: 12). Teknolojik gelişmelerin yaşanması ve rekabet şartlarının değişmesi, varlıklarını sürdürmeleri konusunda işletmeleri derinden etkilemekte ve bu aşamada üretilen muhasebe bilgilerinin kaliteli olmaları işletmenin faaliyetlerinin verimli ve etkin olması bakımından vazgeçilmez bir unsur haline gelmiştir (Kurnaz vd., 2018: 151).

Muhasebe bilgileri işletmelerin gelecekte varlıklarını sürdürülebilir hale getirmeleri konusunda hayati bir değer taşımaktadır. Nihayetinde, muhasebe bilgileri, gelecekte gerçekleştirilmesi planlanan faaliyetlere ilişkin karar alınması konusunda vazgeçilmez bir öneme sahiptir (Kısakürek ve Pekcan, 2005: 108). Bahsedilen öneminden hareketle muhasebe bilgilerinin; i) kreditörler, yatırımcılar, denetleyici ve düzenleyici otoriteler ile konuya ilgi duyan diğer tarafların kullanmasına yönelik oluşturulan finansal bilgiler, ii) plan, bütçe, kontrl ve değerleme yapılmasına yönelik hazırlanmış olan raporlama araçları gibi unsuları kapsaması gerekmektedir (Selto ve Neuman, 1981: 317). Belirtilen muhasebe bilgilerinin içeriği incelendiğinde; bilgi kullanıcılarının ihtiyacına uygun, gerçekleri yansıtan, doğru, güvenilir, karşılaştırabilir ve hesap verebilir niteliklere uygun bilgileri ifade ettiği anlaşılmaktadır. Bahsedilen unsurların yerine getirilmemesi ya da herhangi birisinin eksik kalması üretilen muhasebe bilgisinin kalitesini olumsuz yönde etkileyeceği açıktır. Sonucunda karar mekanizmalarının geleceğe yönelik alacakları kararlar üzerinde önemli bir tehdit oluşturmaktadır. 
İşletmelerin gerçekleştirmiş oldukları faaliyetleri sonucunda bilgi kullanıcılarına sunmuş oldukları bilgilerinin kalitesinin belirlenmesinde; TMS/TFRS Finansal Raporlamaya İlişkin Kavramsal Çerçeve'de ve ilgili litertürde yapılan çalışmalarda (Bayırlı, 2006, 8-12; Yazan, 2015: 6162; Çukacı, 2005: 12) yukarıda belirtilen çeşitli ölçütler geliştirilmiş̧ir. Belirtilen ölçütler dahilinde hazırlanan kaliteli muhasebe bilgilerinin, sunulan mal ve hizmetlerin maliyetlerinin analiz edilmesi sürecindeki önemi açıktır. Çünkü üretimi söz konusu olan bir mal ya da hizmetin maliyetlerinin doğru ve gerçekçi bir şekilde tespit edilmesi ve analizi de kaliteli muhasebe bilgisi ile mümkün olmaktadır. Aksi durumda maliyet analizlerinin güvenilirliğinin sorgulanması ile karşı karşıya kalınmaktadır. Tutarlı ve güvenilir bir maliyet analizinden bahsedilebilmesi üretilen muhasebe bilgilerinin kalitesine göre şekilleneceği açıktır. Diğer taraftan Türkiye ekonomisi içerisinde faaliyet gösteren muhasebe meslek mensuplarının genellikle muhasebe işlemlerinin kayıt altına alınması ile ilgilendiği bilinmektedir. Dolayısı meslek mensuplarının maliyet analizi konusunda eksiklerinin ortaya çıkarılması ve alınması gereken önlemlere ışık tutulması bakımından bu çalışma bir mihenk taşı rolü üstlenmektedir. Faaliyette bulunan işletme sahip ve yöneticilerine muhasebe mesleğinin yalnızca mali nitelikteki işlemlerine ait bilgilerin kayıt altına alınmasının ötesinde bahsedilen bilgilerden hareketle etkili bir maliyet analizinin yapılması konusunda da meslek mensuplarının donanımlı olmaları önemli bir gerekliliktir. Dolayısı ile çalışmanın izleyen aşamalarında maliyet analizi konusuna açıklık getirilmesinde yarar görülmektedir.

\section{MALIYYET ANALİí}

Rekabetin fazla olduğu globalleşen dünyada işletmelerin ana hedeflerinden biri de kârlllıktır. İstenilen kâr seviyesini yakalamak için işletmelerin üretim ya da hizmet faaliyetleri sürecinde oluşan giderler ile maliyetleri sağlıklı ve etkin bir şekilde tespit ederek düşürmesi gerekmektedir. Bu durum işletmelerde gerçekleş̧irilen maliyet hesaplamasının ya da maliyet analizinin işletmeler için önemli bir yere sahip olduğunu göstermektedir. (Özpeynirci \& Şirin, 2018: 69). Bir mal ya da hizmetin müşteriye sunumu esnasında oluşan maliyetler doğal olarak ürünü ya da hizmeti üreten işletme yönetiminin bilmesi gereken bir bilgidir. Maliyetlerin ilgili mal ve hizmete yüklenmesi işleminin sağlıklı ve tam bir şekilde yerine getirilmesi, mal ya da bir hizmetin üretilmeden önce ki faaliyetlerinden başlayarak nihai olarak son kullanıcılara ulaştırılıncaya kadar geçen süreci içerisinde netleşmektedir (Karasioğlu \& Çam, 2008: 15). Maliyet, mal veya hizmet alımı gibi belirli bir amaca ulaşmak için feda edilen veya vazgeçilen kaynak miktarıdır. Bir sürecin verimli bir şekilde yürütülmesi, maliyetlerin etkin bir şekilde kontrol edilmesine bağlıdır ve maliyetler, ancak daha önce analiz edilmiş ve tanımlanmışsa kontrol edilebilir (Innocent \& Chimezie, 2013: 225).

Maliyetin tanımı farklı şekillerde bulunmaktadır. Bunlardan biri, tüketim amacı ile üretilmiş olan malların ve hizmetlerin ekonomik açıdan toplamı olmaktadır. Başka bir tanımda ise maliyet, belirlenen hedefler doğrultusunda yapılan, üretim ve hizmet neticesinde elde edilen ürün veya hizmet faaliyetleri için katlanılan toplam para ve emek miktarı olmaktadır. Yine maliyet, Mal satın almak için verilen nakit, ekonomik varlığın ekonomik değeri veya mal üretiminde kullanılan varlı̆̆ın veya hizmetin parasal değeri olarak karşımıza gelmektedir (Doğan, 2019: 3). Maliyet analizinin yönetici açısından doğru karar almada idari kontrol süreçlerinde aşağıdaki yararları bulunmaktadır (Yüksel, 1996: 127);

- At1l kapasitenin önlenmesi

- Alternatif kararların belirlenmesi

- Yatırımlarda verimsizliğin giderilmesi

- Masrafların doğru kullanılması

- Ekonomik düşünce alışkanlığının personele öğretilmesi

- Önceki y1llar ile kıyaslamak üzere faaliyetlerin olması olanağı

- Denetim altında malzemelerin kullanılması şeklinde siralanabilmektedir. 
Ürün kalitesi ve üretimin verimliliği yüksek olması, üretim maliyetleri ve tedarik sürelerinin ise düşük olması etkin bir üretim sisteminin özelliğidir. Üretim maliyetleri genel olarak üretim giderlerinden ve direkt hammadde ile malzeme, direkt enerji giderlerinden, üretim maliyetinin unsurları ise malzeme ve direkt hammadde, genel üretim giderlerinden ve işçilik giderlerinden oluşmaktadır (Mete \& Yalçınsoy, 2014: 100). Maliyet analiz süreçlerinde kullanılması düşünülen maliyet veri tabanını destekleyecek bir muhasebe sisteminin alt yapısının işletmede kurulmuş olması, maliyet yönetiminde etkinliğin sağlanması için ilk koşul olmaktadır. Muhasebenin istatistik ve matematiksel yöntemleri kullanım alanları olarak yoğun olan kullanım şekli en başta yönetim ve maliyet muhasebesi gelmektedir. Zira yönetimi zorlayan ölçülemeyen unsurlar, etkin olması sağlanamamaktadır. Maliyet planlanması özellikle, maliyet analizi, maliyet kontrolü, maliyet performans değerlendirilmesi ve karar aşamalarında istatistik ve matematiksel yöntemlerinden destek alınmaktadır. Çözümlemelerde ve sayısal ölçümlerde ciddi oranlarda yarar alınmaktadır (Can \& Öztürk, 2014: 162).

Maliyet analizleri incelenirken temel olarak faaliyet hacminde artışların işletmenin sabit ve değişken giderlerdeki değişime etkisi maliyet-hacim ilişkileri açısından önem arz etmektedir (Büyükmirza, 2013: 327). Maliyet analizleri, yönetim kararlarında kullanılırken maliyet optimazyonunu sağlanması da düşünülmelidir.

Günümüzde artan rekabet ortamında maliyet avantajı yakalabilmek için maliyet analizlerinin önemi artmaktadır. İşletmeler, rekabet avantajını maliyetleri etkin kontrol ederek sağlayabilmektedir. İşletme yönetimi planlama, kontrol ve fiyatlandırma gibi kararları alırken muhasebe biriminden sağlanacak verileri maliyet analizi açısından incelemeli ve etkin maliyet yönetimi oluşturmalıdır (Kartal \& Sevim, 2019: 3). Bu noktada muhasebe biriminden elde edilecek olan bilgilerin kalitesi büyük önem taşımaktadır. Çünkü işletmenin gelecekte varlığını devam ettirmesi, kısa, orta ve uzun vadeli stratejik kararların alınmasının arkasında kaliteli muhasebe bilgileri yer almaktadır. $\mathrm{Bu}$ noktada çalışmanın izleyen aşamalarında muhasebe bilgi kalitesinin maliyet analizi süreçlerine ilişkin uygulamaya yer verildiğini belirtmekte yarar görülmektedir.

\section{YÖNTEM VE UYGULAMA}

Çalışmanın bu bölümünde; araştırmanın amacı ve önemi, kapsamı ve kısıtı, verilerin elde edilmesi ve analizi ile ulaşılan bulgulara yer verilmekte olup aşağıda ayrıntılı bir biçimde açıklanmaktadır.

\subsection{Araştırmanın Amacı ve Önemi}

$\mathrm{Bu}$ araştırmada Gaziantep ilinde faaliyet gösteren muhasebe meslek mensuplarının muhasebe bilgi kalitesinin maliyet süreçleri üzerindeki etkisine yönelik görüşlerinin belirlenmesi amaçlanmıştır. Kaliteli muhasebe bilgilerinin üretilmesi ile maliyet analizlerinin daha tutarlı ve doğru bir şekilde yapılması bakımından bu çalışma ayrı bir önem taşımaktadır. Maliyet analizleri sonucunda; yöneticiler tarafından etkili bir planlamanın yapılması, fiyatlandırma kararları gibi konular muhasebe bilgilerinin kalitesine bağlı olarak şekillendiği açıktır. Dolayısıyla bu çalışma maliyet analizi süreçlerinin kaliteli muhasebe bilgileri 1şığında yeniden yapılandırılması konusunda rehber olabilecektir.

\subsection{Araştırmanın Kapsamı ve Kısıtı}

Araştırma, Gaziantep ilinde Serbest Muhasebeci Mali Müşavirler Odası'na kayıtlı olan meslek mensuplarını kapsamakta ve doğru, tutarlı ve güvenilir bilgilerin elde edilmesi ve sonuçlarının doğru bir şekilde yorumlanabilmesi bakımından maliyet analizi konusunda uzman ve sertifika sahibi olan meslek mensupları araştırmanın önemli bir kısıtı olarak kabul edilmiştir. 


\subsection{Verilerin Elde Edilmesi ve Analizi}

Araştırma için veriler anket tekniği ile yüz yüze 2020 yılında muhasebe meslek mensuplarına uygulanmıştır. Uygulanan anketlerin içeriğin oluşturulmasında daha önce güvenilirliği kanıtlanmış çalışmadan (Cohen, Manion \& Marrison, 2007) yararlanılmıştır. Ayrıca anket soruları hazırlanırken SMMM Odası yöneticilerinin düşüncelerinden ve bilhassa Aktaş \& Turan (2019) çalışmalarından faydalanılmıştır. Oluşturulan anket formu 22 soru ve 2 gruptan oluşturulmuş ve etik kurallara aykırılık oluşturmadığına dair ilgili kurul kararı alınmıştır. Her bir ifade 1'den 5 'e kadar kodlanmış ve katılma dereceleri "Kesinlikle Katılmiyorum", "Katılmıyorum", "Ne Katıllyorum Ne Katılmiyorum", "Katıllyorum" ve "Kesinlikle Katıllyorum” şeklindedir. Birinci grupta; katılımcıların demografik ve betimsel özelliklerin belirlenmesine yönelik; cevaplayanın pozisyonu, yaşı, cinsiyeti ve eğitim durumuna ilişkin ifadeler yer almaktadır. İkinci grup sorularda, muhasebe bilgi kalitesinin maliyet analizi süreçlerine etkisinin belirlenmesine yönelik 17 ifade yer almaktadır. Anketlerden elde edilen veriler toplanarak düzenlenmiş ve araştırmanın amacına ve niteliğine uygun olarak gözden geçirilerek kodlanmıştır. Uygulamanın gerçekleştirilmesi bakımından 250 adet anket formu dağıtılmış ve elde edilen 160 adet anket formundan 152 adedi değerlendirmeye uygun görülmüş̧ür. Elde edilen veriler, "Microsoft Excel 2016" programinda kodlanarak "SPSS (Statistical Package for the Social Sciences) 24.0" programına aktarılmış olup bu programda uygun analizler yapılmış ve (güvenirlik analizi, tanımlayıcı istatistikler, frekans dă̆llımı, parametrik olmayan varyans analizi; Kruskal Wallis H testi ve Mann-Whitney U testi) ve sonuçlar düzenlenerek değerlendirilmiştir.

İstatistiksel testlerin uygulanabilmesi bazı varsayımların sağlanmasına bağlı olduğu karşımıza çıkmaktadır. Söz konusu varsayımların en önemlisi olarak ilgilenilen dağılımın normal dağılıma uygun olması olarak kabul edilmektedir. Uygulamada pek çok durumda verilerin normal dağılım sergileyen bir anakütleden geldiği varsayılmakta olup bu durumun sebebi ise doğa ve insan davranışlarının genel olarak normal dağılım ile bağdaştırılması çabası olduğu görülmektedir (Özdamar, 2013: 103). Bu bağlamda parametrik testlerin uygulanabilmesi bakımından; geçerlilik testleri sonucunda normal dağılım göstermemiş bir veri setinin olması durumunda ya da normal dağılım varsayımı kullanılmak istenmiyorsa, parametrik olmayan testler kullanılabilmektedir (Baş, 2019: 96). Parametrik olmayan testlerin uygulanabilmesi açısından ise verilerin, bağımsız ve tesadüfi olarak elde edilmesi, sıralayıcı ya da sınıflayıcı ölçekle ölçülmesi ve normal dağılım özelliği göstermemesi yeterli kabul edilmektedir (Karagöz, 2010: 19). Verilerin tesadüfi olarak seçildiği bu çalışmada; verilerin normal dağılıma sahip olup olmadığ 1 test edilmiş ve verilerin normal dağılıma sahip olmamasından dolayı iki grubun karşılaştırılmasında parametrik olmayan t Testi (MannWhitney $U$ ), ikiden fazla grubun karşılaştırılmasında parametrik olmayan varyans analizi (Kruskal Wallis $H$ testi) ve tercih edilmiştir.

Parametrik olmayan tek yönlü varyans analizi olarak ifade edilen Kruskal Wallis $H$ testi; k bağımsız örneğin x puanlarına ait dağılımın benzer ortancaya sahip toplumların rastgele örnekleri olup olmadığı test edilmek istendiğinde kullanılmaktadır (Baş, Kurnaz \& Kestane, 2019: 253-254). Üç farklı üniversiteden ele alınan öğretim üyelerinin iş tatmin puanları arasında fark olup olmadığının test edilmesi örnek olarak gösterilebilmektedir.

İki ana kütlenin benzer dağılıma sahip olup olmadığının tespit edilmesinde kullanılan MannWhitney $U$ testi; parametrik testlerde yer alan t-testinin parametrik olmayan alternatifi olarak kullanılmaktadır (Bayram, 2017: 116). Kız ve erkek öğrencilerinin stres puanlarının birbirinden farklı olup olmadığının belirlenmesi, örnek olarak gösterilebilmektedir. (Kestane, 2020: 267).

\subsection{Bulgular ve Değerlendirme}

Araştırmanın bu bölümünde, (i) araştırmanın güvenirliğine ilişkin bilgiler, (ii) katılımcıların demografik özelliklerine ilişkin ulaşılan bilgiler; (ii) muhasebe meslek mensuplarının, muhasebe 
bilgi kalitesinin maliyet süreçlerine etkisinin belirlenmesine yönelik ifadelerinin ortalama değerlerine ilişkin sonuçlar ile (iii) Kruskal Wallis $H$ testi ve (iv) Mann-Whitney U testi sonuçları özetlenerek yorumlanmaktadır. Bu aşamada, istatistiksel olarak anlamlı farkl1liklar bulunan sonuçların aşağıda açıklanarak yorumlandığını belirtmekte yarar görülmektedir.

Araştırmada anket tekniği ile elde edilen verilerinin güvenilir, tesadüfi ve tutarlı olup olmadı̆̆ını belirlemek için güvenirlilik analizi yapılmıştır. Bu analiz sonucu elde edilen Cranbach's Alpha'nın (güvenirlilik katsayı değeri- $\alpha$ ) 0,80-1,00 arası çıkması durumunda, örneklemden elde edilen verilerin yüksek derecede güvenilir olduğu anlamına gelmektedir (Yıldız \& Uzunsakal, 2018: 19). Bu çalışmada ise tüm katılımcıların yer aldı̆̆ veriler için güvenirlik analizi yapılmış ve $\propto$ değeri 0,959 çıkmıştır. Elde edilen sonuç çalışmanın yüksek derecede güvenilir olduğunu göstermektedir.

Tablo 1: Muhasebe Meslek Mensuplarının Demografik Özellikleri

\begin{tabular}{|c|c|c|c|c|c|c|c|}
\hline \multicolumn{2}{|c|}{ Açıklama } & \multirow{2}{*}{$\frac{\text { Sayı }}{35}$} & \multirow{2}{*}{$\frac{\text { Yüzde (\%) }}{24,1}$} & \multicolumn{2}{|r|}{ Açıklama } & \multirow{2}{*}{$\frac{\text { Sayı }}{22}$} & \multirow{2}{*}{$\frac{\text { Yüzde (\%) }}{15,2}$} \\
\hline \multirow{6}{*}{ Deneyim } & $1-5 Y_{11}$ & & & & 20-30 Yaş Arası & & \\
\hline & 6-10 Yil & 28 & 19,3 & & 31-40 Yaş Arası & 64 & 44,1 \\
\hline & 11-20 Y1l & 53 & 36,6 & Yaş & 41-50 Yaş Arası & 55 & 37,9 \\
\hline & 21-30 Y1l & 26 & 17,9 & & 51-60 Yaş Arası & 4 & 2,8 \\
\hline & 30 Yıl ve Üzeri & 3 & 2,1 & & 61 Yaş ve Üzeri & -- & -- \\
\hline & Toplam & 145 & 100 & & Toplam & 145 & 100 \\
\hline \multirow{3}{*}{ Eğitim } & Lisans & 128 & 88,3 & Cinsiyet & Bayan & 36 & 26,4 \\
\hline & Lisans Üstü & 17 & 11,7 & & Erkek & 109 & 73,26 \\
\hline & Toplam & 145 & 100 & & Toplam & 145 & 100 \\
\hline
\end{tabular}

Tablo 1'e bakıldığında araştırmaya katılan muhasebe meslek mensuplarının büyük bir çoğunluğunun yaşlarının $31-40$ yaş $(\% 44,1)$ aralığında olduğu görülmektedir. Araştırmaya katılanların $36(\% 26,4)$ kişisi bayan ve $109(\% 73,26)$ kişisi erkektir. Muhasebe meslek mensuplarının eğitim durumu ise; lisans $128(\% 88,3)$ kişi ve lisans üstü dereceye sahip olan ise $17(\% 11,7)$ kişi şeklinde dağılmıştır.

Tablo 2: Muhasebe Bilgi Kalitesinin Maliyet Analizi Süreçlerine Etkisine İlişkin Görüşlerin Ortalama Değerleri

\begin{tabular}{|c|c|c|c|c|}
\hline No & İfadeler & Min. & Maks. & Ort. \\
\hline 1 & Muhasebe Bilgisinin Kaliteli olması iş memnuniyetimi artırmaktadır. & 1 & 5 & 4,73 \\
\hline 2 & $\begin{array}{l}\text { Muhasebe Bilgisinin Kaliteli olması işletmedeki birimler arasında etkileşimi } \\
\text { artırmaktadır. }\end{array}$ & 1 & 5 & 4,77 \\
\hline 3 & Muhasebe Bilgisinin Kaliteli olması fiyatlandırma kararlarına olumlu yansımaktadır. & 1 & 5 & 4,62 \\
\hline 4 & Muhasebe Bilgisinin Kaliteli olması maliyetlerin kontrolünü sağlamaktadır. & 1 & 5 & 4,7 \\
\hline 5 & Muhasebe Bilgisinin Kaliteli olması iş performansıma katkıda bulunmaktadır. & 1 & 5 & 4,62 \\
\hline 6 & $\begin{array}{l}\text { Muhasebe Bilgisinin Kaliteli olması faaliyetlerin planlanmasına ve kontrolüne olumlu } \\
\text { etki sunmaktadır. }\end{array}$ & 1 & 5 & 4,65 \\
\hline 7 & $\begin{array}{l}\text { Muhasebe Bilgisinin Kaliteli olması maliyetlerin azaltması çalışmalarına fayda } \\
\text { sağlamaktadır. }\end{array}$ & 1 & 5 & 4,56 \\
\hline 8 & $\begin{array}{l}\text { Muhasebe Bilgisinin Kaliteli olması genel üretim giderlerinin dağıtımını daha sağlıklı bir } \\
\text { hale getirmiştir. }\end{array}$ & 1 & 5 & 4,61 \\
\hline 9 & $\begin{array}{l}\text { Muhasebe Bilgisinin Kaliteli olması mamul maliyetlerinin hesaplanması esnasında rol } \\
\text { alan önemli bir faktördür. }\end{array}$ & 1 & 5 & 4,64 \\
\hline 10 & Muhasebe Bilgisinin Kaliteli olması üretim sürecinin iyileşmesine katkı sunmaktadır. & 1 & 5 & 4,59 \\
\hline 11 & $\begin{array}{l}\text { Muhasebe Bilgisinin Kaliteli olması işletmedeki atıl durumu göz önüne serilmesini sağlar. } \\
\text { Muhasebe Bilgisinin Kaliteli olması karar alma süreçleri esnasında kullanılan bilgilerin }\end{array}$ & 1 & 5 & 4,57 \\
\hline 12 & önemini artırmaktadır. & 1 & 5 & 4,66 \\
\hline
\end{tabular}


Tablo 2 (Devamı): Muhasebe Bilgi Kalitesinin Maliyet Analizi Süreçlerine Etkisine İlişkin Görüşlerin Ortalama Değerleri

\begin{tabular}{|c|c|c|c|c|}
\hline 13 & $\begin{array}{l}\text { Muhasebe Bilgisinin Kaliteli olması yatırım kararlarını alma sürecine olumlu katkılar } \\
\text { sağlar. }\end{array}$ & 1 & 5 & 4,65 \\
\hline 14 & $\begin{array}{l}\text { Muhasebe Bilgisinin Kaliteli olması maliyet analizlerinin sonuçlarının daha doğru } \\
\text { olmasını sağlar. }\end{array}$ & 1 & 5 & 4,7 \\
\hline 15 & Muhasebe Bilgisinin Kaliteli olması işletmenin rekabet gücünü artırır. & 1 & 5 & 4,51 \\
\hline 16 & Muhasebe Bilgisinin Kaliteli olması bütçeleme sistemine olumlu katkı sağlamaktadır. & 1 & 5 & 4,61 \\
\hline 17 & Muhasebe Bilgisinin Kaliteli olması iş süreçlerinin daha kolay olmasını sağlar. & 1 & 5 & 4,66 \\
\hline
\end{tabular}

Muhasebe meslek mensuplarının muhasebe bilgi kalitesinin maliyet analizi süreçlerine etkisini ölçen ifadelere katılım düzeyleri Tablo 2'de verilmiştir. Muhasebe meslek mensuplarının ifadelere verdikleri cevapların ortalama değeri 4,54 olmuştur. $\mathrm{Bu}$ durumda katılımcılar $\% 91$ oranında muhasebe bilgi kalitesinin maliyet analizi faaliyetlerine olumlu etkisi olduğunu belirtmiştir.

Tablo 3: Muhasebe Meslek Mensuplarının Eğitim Durumlarına Göre Mann-Whitney U (t Testi) Sonuçları

\begin{tabular}{cccc}
\hline \multicolumn{4}{c}{ Muhasebe Meslek Mensuplarının Eğitim Durumlarına Göre Mann-Whitney U (t Testi) Sonuçları } \\
\hline İfade & Mann-Whitney U & Wilcoxon W & p (2-tailed) \\
\cline { 2 - 4 } 4 & 35,000 & 45,000 &, 008 \\
6 & 42,000 & 52,000 &, 023 \\
9 & 48,500 & 58,500 &, 039 \\
20 & 41,500 & 51,500 &, 011 \\
22 & 31,000 & 41,000 &, 014 \\
\hline
\end{tabular}

Anlamlılık dĕgeri; $p<0,05$

Tablo 3'e bakıldığında, muhasebe meslek mensuplarının, maliyet analizi süreçleri üzerinde muhasebe bilgi kalitesinin etkisine ilişkin tutumlarının; “ $p<0,05$ ”’ten küçük olan 4, 6, 9, 20 ve 22 . ifadeleri kapsamında istatistiksel olarak anlamlı bir farklılık gösterdiği tespit edilmiştir. Bu durum muhasebe meslek mensuplarının ilgili ifadelere yönelik tutumlarının lisans, lisansüstü eğitim mezunlarına göre farklılık gösterdiği anlamına gelmekte olup muhasebe meslek mensuplarının eğitim durumlarının gerçekleştirilen maliyet analizi süreçleri üzerinde kullanılan muhasebe bilgilerinin kalitesinin istatistiksel olarak anlamlı bir etki sahibi olduğunu işaret etmektedir. Daha açık bir ifade ile maliyet kontrolü, faaliyet planlaması, mamul maliyetinin hesaplanması, rekabet gücü ve iş süreçlerinin kolaylaştırılması konularında sunulan muhasebe bilgilerinin kalitesinin, muhasebe meslek mensuplarının eğitim durumlarına göre anlamlı bir farklılık gösterdiği sonucuna ulaşılmıştır. Daha yüksek eğitime sahip olan muhasebe meslek mensuplarının; ilgili konularda muhasebe bilgi kalitesinin maliyet analizi süreçleri üzerinde anlamlı bir etkiye sahip olduğu görüşünü benimsedikleri anlaşılmaktadır. Muhasebe meslek mensuplarının maliyet analizi süreçleri üzerinde muhasebe bilgi kalitesinin etkisine ilişkin tutumlarının; sahip oldukları cinsiyet, pozisyon, yaş ve deneyimleri bağlamında istatistiksel olarak anlamlı bir farklılık göstermediği sonucuna ulaşılmıştır. Dolaysıyla, cinsiyet, pozisyon, yaş ve deneyim gibi unsurların; maliyet analizi süreçleri üzerinde herhangi bir etkisinin olmadı̆̆ını söylemek mümkündür.

Ulaşılan bulgular bütünleşik olarak değerlendirildiğinde; muhasebe bilgi kalitesinin maliyet analizi süreçleri üzerinde; muhasebe meslek mensuplarının eğitim durumlarına göre anlamlı bir farklılık gösterdiği fakat cinsiyet, pozisyon, yaş ve deneyimlerinin herhangi bir etki sahibi olmadığ1 tespit edilmiştir. Elde edilen bulgulardan hareketle muhasebe meslek mensuplarına maliyet analizi konusunda, eğitimler yoluyla deneyim kazandırılmasının gerekliliği ortaya çıkmıştır. Çünkü cinsiyet 
ve yaş değişkenleri karşısında deneyim sahibi olmanın ve ilgili deneyimlerin sahaya yansıtılmasının getireceği katma değerin daha yüksek olabileceği açıktır.

\section{SONUÇ}

Muhasebe ve muhasebe bilgi sistemleri tarafindan üretilen bilgilere işletmelerin gerçekleştirdiği faaliyetlerin her sürecinde ihtiyaç duyulmaktadır. Globalleşme sürecinde meydana gelen teknolojik gelişimler ve rekabet ortamının değişmesi, işletmelerin daha efektif ve etkin çalışmaları gereksinimlerini ortaya koymaktır, bu husus ise günümüzde muhasebe bilgilerindeki kalitenin önemini artırmaktadır. İşletmelerin rekabet ortamında üstün olmalarını sağlayan kriterlerden biri maliyet odaklı olmaktır ve dolayısıyla bu kriter iletmelerin geleceğe emin adımlarla taşınması ile varlıklarını sürdürebilme hususunda etkin bir performans göstergesidir. İşletmelerin yaptıkları maliyet analizi faaliyetleri bu noktada önemini ortaya koymaktadır. Maliyet analizi süreçlerinde de işletmelerin diğer faaliyetlerinde olduğu gibi muhasebe ve muhasebe bilgi sistemlerinin ürettiği bilgilerden faydalanılmaktadır. Bilginin doğruluğu diğer bir mana ile kaliteli oluşu maliyet analizi süreçlerinin de etkin ve verimli olacağını göstermektedir. Aynı zamanda maliyet analizinin etkin ve verimli olması işletme yöneticilerinin kararlarını da olumlu yönde etkileyecektir.

Gaziantep Bölgesinde bulunan muhasebe meslek mensupları tarafından muhasebe bilgi kalitesi ile maliyet analizi süreçlerinin etkileşiminin hangi doğrulta olduğunun saptanması hedeflenmiştir. Benzer çalışmalarda da maliyet analizinin işletmelere rekabet avantajı sağladığ 1 ve istenilen sonuçlara ulaşılmasını desteklediği görülmektedir. Abdelraheem vd. (2021) bilgi teknolojilerinin muhasebe bilgi kalitesini artırdığı; Fangyuan \& Ying (2020) yüksek kaliteye sahip muhasebe bilgilerinin finansman maliyetlerini düşürerek potansiyel yatırımcılara daha fazla güven oluşturduğu; Nguyen \& Nguyen (2020) yöneticilerin donanım düzeyleri ile organizasyon kültürünün muhasebe bilgi kalitesini etkilediği; Karesioğlu \& Çam (2008) sağl1k işletmelerinde doğru ve etkin bir maliyet analizi ile muayene maliyetlerinin minimize edilebileceği sonuçlarına ulaşmışlardır. Bahsedilen çalışmalar ile bu çalışmanın sonuçları incelendiğinde; muhasebe bilgi kalitesinin, maliyetlerin tespiti, analizi ve yönetilmesi konularında örtüştüğünü belirtmek mümkündür. Ayrıca ilgili literatür incelendiğinde muhasebe bilgi kalitesi ve maliyet analizinin yerli ve yabancı literatürde bütünleşik olarak çok sığ bir biçimde incelendiği tespit edilmiştir. Bu çalışma ile Türk literatüründe ilgili alanda oluşan bilgi boşluğuna katkıda bulunulacağı açıktır.

Muhasebe bilgisinin kalitesinin fazla olması muhasebe meslek mensuplarının iş memnuniyetini arttırdığı ve işletme içindeki birimleri arasındaki etkileşime faydası olacağı açıktır. Ayrıca kaliteli muhasebe bilgilerinin, maliyet analizinin temelini oluşturan doğru fiyatlandırma, maliyetlerin azaltması ve maliyetlerin kontrolü noktasında pozitif etkiler bıraktığı kanısı oluşmuştur. İşletmelerin sürdürebilirliği, etkin maliyet analizi ile mümkün olabilmektedir. Mali faaliyetlerin planlanması, mamul maliyetlerinin hesaplanması, genel üretim giderlerinin dağıtımı ve bütçeleme sistemi muhasebe bilgisinin kaliteli olması ile daha sağlıklı bir hal almıştır. Kaliteli muhasebe bilgisi ile işletme yöneticileri daha sağlıklı yatırım kararı alacaklardır ve işletmenin rekabet gücü artacaktır. Ayrıca, muhasebe bilgi kalitesinin etkinliği işletmelerin doğru stratejik kararlar almalarına da katkıda bulunacaktır. Kaliteli muhasebe bilgisinin, işletmelerin rekabetçi küresel piyasalara hazırlanmasında etkin rol oynamaya başladığı güncel gelişmelerden açıkça görülebilmektedir.

\section{KAYNAKÇA}

Abdelraheem, A.A.E., Hussaien, A. M., Mohammed, M. A. A. \& Albokhari, Y. A. E. (2021). The Effect Of İnformation Technology On The Quality Of Accounting İnformation. Accounting, 7, 191-196.

Acar, D., \& Özçelik, H. (2011). Muhasebe Bilgi Kalitesini Etkileyen Kritik Başarı Faktörleri. Muhasebe ve Finansman Dergisi, 10-23. 
Aktaş, R. \& Turan, Z. (2019). İşletmelerde Maliyet Sistemleri Kullanımlarının İncelenmesi: Manisa Organize Sanayi Bölgesi Örneği. İşletme Araştırmaları Dergisi Journal Of Business ResearchTürk, 11(1), 249-272

Ala, T., Kahraman, T., \& Sümer, E. (2016 ). Muhasebe Bilgi Kalitesi: Karşılaştırılabilirlik Kavramı. Süleyman Demirel Üniversitesi Sosyal Bilimler Entitüsü Dergisi, 140-152.

Arıcı, N.D., \& Karğın, M. (2017). Muhasebe Bilgilerinin Kalitesini Etkileyen Faktörler Üzerine Bir Literatür İncelemesi. Yönetim ve Ekonomi, 215-232.

Basu, A. \& Manning, B.G. (2009). Issues for the Next Generation of Health Care Cost Analyses. JSTOR, 47(7), 109-114.

Baş, M. (2019). Bağlantılı K Örneklem ile Parametrik Olmayan Cochran Q Testi: BIST 100 Uygulaması. Uluslararası Afro-Avrasya Araştırmaları Dergisi, 4(8), 94-107.

Baş, M., Kurnaz, N. \& Kestane, A. (2019). Studies On Interdisciplinary Economics And Business Volume II. In Özçelik, Ö. (Eds.) Statistical Analysis Of Corporate Sustainability In The TRNC Banking Sector After The Crisis (pp. 249-276), Berlin: Perter Lang.

Bayırlı, R. (2006). Yaratıcı Muhasebe, Etik, Firma Değeri ve Örnek Bir Uygulama, Doktora Tezi, Gazi Üniversitesi, Sosyal Bilimler Enstitüsü, Ankara.

Bayram, N. (2017). Sosyal Bilimlerde SPSS ile Illeri Veri Analizi. Isparta: Ezgi Kitabevi.

Büyükmirza H.K. (2013). Maliyet ve Yönetim Muhasebesi, Ankara: Gazi Kitabevi.

Can, A.V., \& Öztürk, E. (2014). Maliyet Yönetiminde Etkinliğin Artırılmasına İlişkin Bir Yöntem Önerisi:Maliyet-Hacim-Risk Analizi(Mhra). Niğde Üniversitesi İibf Dergisi, 161-174.

Chan, A., Lee, E. \& Lin, S. (2006). The İmpact Of Accounting İnformation Quality On The Mispricing Of Accruals: The Case Of FRS3 İn The UK. J. Account. Public Policy, 28, 189206.

Cohen, L., Manion, L. \& Morrison, K. (2007). Research Methods in Education. Oxon: Routledge.

Çukacı, Y.C. (2005). Ekonomik Değer Olarak Bilginin Muhasebe, İşletmeler ve Genel Ekonomi Açısından Değerlendirilmesi, Doğu Anadolu Bölgesi Araştırmaları, 3(3), 11-19.

Dalkılıç, E. (2019). Muhasebe Bilgi Kalitesinin Firma Performansı ve Firma Değeri Üzerine Etkisinin Incelenmesi. Yüksek Lisans Tezi. Erciyes Üniversitesi Sosyal Bilimler Enstitüsü. Kayseri.

Demir, B. (2010). Muhasebe Bilgi Sistemlerinde Bilgi Kalitesi. Muhasebe ve Finansman Dergisi, 142-153.

Dinç, E., \& Abdioğlu, H. (2009). İşletmelerde Kurumsal Yönetim Anlayışı Ve Muhasebe Bilgi Sistemi İlişkisi: İmkb-100 Şirketleri Üzerine Ampirik Bir Araştırma. Balıkesir Üniversitesi Sosyal Bilimler Enstitüsü Dergisi, 157-184.

Doğan, E.N. (2019). Yönetim Ekonomisinde Maliyet, Maliyet Analizi ve Uygulaması. İstanbul: T.C İstanbul Kültür Üniversitesi Lisansüstü Eğitim Enstitüsü.

Elitaş, B.L. (2013). Muhasebe Manipülasyonu ve Muhasebe Bilgi Kalitesine Etkisi. Muhasebe ve Finansman Dergisi, 41-54.

Fangyuan, W. \& Ying, L. (2020). Quality of Accounting Information Disclosure and Debt Financing Cost: Literature Review. International Journal of Accounting, Finance and Risk Management, 5(4), 191-194

Fardinal, K. (2013). The Quality Of Accounting Information And The Accounting Information System Through The Internal Control Systems: A Study On Ministry And State Agencies Of The Republic Of Indonesia. Research Journal Of Finance And Accounting, 4(6), 156- 161.

Gençoğlu, Ü. G., \& Ertan, Y. (2012). Muhasebe Kalitesini Etkileyen Faktörler ve Türkiye'deki Durum. Muhasebe ve Finansman Dergisi , 1-24.

Handy, F. \& Mook, L. (2011). Volunteering and Volunteers: Benefit Cost Analyses. Research on Social Work Practice, 21(4) 412-420.

Innocent, N. \& Chimezie, N. (2013). Principles Of Costıng And Cost Analysis As A Tool For Production Costs Control: A Case Study Of Nigerian Companies. Research Journal In Engineering And Applied Sciences, 225-229. 
Karagöz, Y. (2010). Nonparametrik tekniklerin güç ve etkinlikleri. Elektronik Sosyal Bilimler Dergisi, 9(33), 18-40.

Karasioğlu, F., \& Çam, A.V. (2008). Sağlık İşletmelerinde Maliyet Analizi: Karaman Devlet Hastanesinde Birim Muayene Maliyetlerinin Hesaplanması. Ni ̌̆de Üniversitesi İ̈BF Dergisi, $15-24$.

Karğın, M., \& Arıcı, N.D. (2015). Muhasebe Bilgilerinin Kalitesini Ölçmeye Yönelik Bir Çalışma: Borsa İstanbul. Muhasebe ve Finansman Dergisi, 1-22.

Kartal,A., \& Sevim, A. (Edit.) (2019). Maliyet Yönetimi, Eskişehir: Anadolu Üniversitesi Yayınları No: 3034.

Kaya, E. (2019). Muhasebe Bilgi Kalitesinin Çok Boyutlu Ölçümü: Borsa İstanbul Uygulaması. İzmir İktisat Dergisi, 157-170.

Keleş, N. (2018). Karadeniz Bölgesi’nde Muhasebe Bilgi Kalitesi Boyutlarının Incelenmesi. Karadeniz Teknik Üniversitesi Sosyal Bilimler Enstitüsü, Trabzon.

Kestane, A. (2020). Studies On Interdisciplinary Economics And Business -Volume III in Özçelik, Ö. (Eds.) The Role Of Internal Control System In Strengthening Corporate Management In Banks: Provincial Case Of Kilis, (pp. 263-281). Berlin: Peter Lang.

Kısakürek, M. M. \& Pekcan, A. (2005). Muhasebenin Ürettiği Bilgiye Farklı Açılardan Bakışlar. C. Ü. İktisadi ve İdari Bilimler Dergisi, 6(2), 107-125.

Kudra, T. \& Ratti, C. (2006). Foam-Mat Drying: Energy And Cost Analyses. Canadıan Bıosystems Engineering, 48, 27-32.

Kurnaz, N., Ercan, C., \& Kestane, A. (2018). Muhasebe Bilgi Kalitesi Ekseninde İç Denetim ve Bilgi İfşası (Whistleblowing). Kastamonu Üniversitesi İktisadi ve İdari Bilimler Fakültesi Dergisi, $150-169$.

Mete, M., \& Yalçınsoy, A. (2014). Maliyet Etkinliği Açısından Bilgi Teknolojilerinin Üretim Maliyetleri Üzerine Etkisinin Analizi. Turan-Sam Uluslararası Bilimsel Hakemli Dergisi, 95107.

Nguyen, H.T. \& Nguyen, A. H. (2020). Determinants Of Accounting İnformation Systems Quality: Empirical Evidence From Vietnam. Accounting, 6, 185-198.

Özdamar, K. (2013). Paket Programlar ile İstatistiksel Veri Analizi I. Eskişehir: Nisan Kitabevi.

Özpeynirci, R., \& Şirin, H. B. (2018). Endüstriyel Makine İmalatı Yapan İşletmelerde Maliyet Sisteminin Oluşturulması ve Bir Uygulama. KMÜ Sosyal ve Ekonomik Araştırmalar Dergisi, 59-71.

Ren, C. (2016). The Approach Of Accounting Information Quality On Investment EfficiencyEmpirical Evidence From Chinese Listed Companies. Theoretical Economics Letters, 6, 330337.

Selto, F.H, \& Neumann, B.R. (1981). A Further Guide to Research on the Consequences of Accounting. Accounting And Business Research, Autumn, 317-322.

Sevilengül, O. (2020). Genel Muhasebe (19. Baskl). Ankara: Gazi Kitabevi.

TMS/TFRS: Finansal Raporlamaya İlişkin Kavramsal Çerçeve. URL, (ET: 01.01.2020).

Türk Dil Kurumu (TDK), (2020), Muhasebe. URL, (ET: 02.01.2020)

Yazan, Ö. (2015). Muhasebe Bilgi Kalitesi Açısından Kurumsal Sosyal Sorumluluk, Kazanç Yönetimi ve Finansal Performans İlişkisi, Doktora Tezi, Karadeniz Teknik Üniversitesi, Sosyal Bilimler Enstitüsü, Trabzon.

Yıldız, D. \& Uzunsakal, E. (2018). Alan Araştırmalarında Güvenilirlik Testlerinin Karşılaştırılması ve Tarımsal Veriler Üzerine Bir Uygulama. Uygulamalı Sosyal Bilimler Dergisi, 1, 14-28.

Y1lmaz, B., Bülbül, S., \& Atik, M. (2017). Büyük Verinin (Big Data) Muhasebe Üzerindeki Etkisi ve Muhasebeye Sağladığı Katkıların İncelenmesi. Kara Harp Okulu Bilim Dergisi, 79-112.

Yüksel, A. (1996). Hastanelerde Maliyet Analizi. Tepecik Ĕ̆itim ve Araştırma Hastanesi Dergisi, 126-129.

Zhai, J. \& Wang, Y. (2016). Accounting Information Quality, Governance Efficiency and Capital Investment Choice. China Journal Of Accounting Research, 9, 251-266. 